\title{
Effects of exercise and nutrition education programs on motor function and eating habit in mild dementia patients
}

\author{
Min-Soo Cho', Ji-Youn Kim,* \\ ${ }^{1}$ Liberal Arts College, Chungwoon University, Incheon, Korea \\ ${ }^{2}$ Exercise Rehabilitation Convergence Institute, Gachon University, Incheon, Korea
}

The purpose of this study was to investigate the effects of physical activity and nutrition education programs on mild dementia patients with changes in exercise function and eating habits. We examined the effects of pre and post program on 23 old patients with dementia who were diagnosed with menarche or mild dementia with the permission of the dementia center in Incheon city and visited from April to July 2017. The Mini-Mental State Examination score of the subjects in this study was $19.68 \pm 3.25$, consisting of mild dementia patients. After performing the program for 16 weeks, the senior fitness test showed a significant change in the arm curl test, chair sit-and-reach test, and 2-min step test, and a total score of mini nutrition assessment increased from 19.16 to 21.0. In particular, in a level 2 evaluation, which contains more details such as the condition of taking drugs, number of daily meals, protein food intake condition, intake of vegetables, fruit, and water, whether one can eat alone, and evaluation of nutritive condition, a significant increase from 9.78 to 11.28 was verified. There is a significant increase in nutrition condition recovery as a result of nutrition education. In comparing pre and post program, a significant result was confirmed, and there was significance to provide the basic empirical data for the exercise and dietary life nutritional education of mild dementia patients.

Keywords: Mild dementia patient, Exercise, Nutritional education, Exercise function, Eating habits

\section{INTRODUCTION}

Hereditary factors, lifestyle, natural environment, sociocultural environment, physical performance, nutritional factors, and medical care are suggested as various factors that contribute to healthy longevity. Among these, it is known that lifestyle and nutritional factors affect more than $50 \%$ of successful aging (Gaudreau et al., 2007; Ozaki et al., 2007).

Among the aging population over 65 years in Korea, 9.58\% $(610,000$ people) are dementia patients as of 2014 , and it this is expected to increase to $10.39 \%$ (840,000 people) by 2020 and $15.06 \%$ (2,170,000 people) by 2050 (Korea National Statistical Office, 2011). This is not only a problem in Korea, as more than 36 million people are affected by dementia around the world. Considering the global population's aging trend and high burden of disease, it can be said that this is a significant economic and so- cial problem in the world (American Psychiatric Association, 2013).

Dementia is a group of acquired diseases that present as clinically significant defects in cognitive function, and it is included in neurocognitive disorders in the Diagnostic and Statistical Manual of Mental Disorders-5 (Todde et al., 2016). Alzheimer disease, which is the most common cause of dementia, shows a prevalence rate of $5 \%-10 \%$ in the aging population over 65 years, and it causes cognitive decline which progresses gradually, along with difficulty in performing daily life activities and changes in behavior and mood.

As bed rest time gets longer according to the decline in physical activities due to physical changes in the old people with dementia, there is exposure to constipation and bedsores, a decrease in appetite, and increase in indigestion (Kwong et al., 2009) as well as pneumonia and infectious diseases (Kim et al., 2011). It is also reported that there is an increasing danger of fractures (Landi et al., 2010) as a result of decreasing muscular strength and weakening
${ }^{*}$ Corresponding author: Ji-Youn Kim (iD https://orcid.org/0000-0003-2325-1921 Exercise Rehabilitation Convergence Institute, Gachon University,

191 Hambangmoe-ro, Yeonsu-gu, Incheon 21936, Korea

E-mail: eve14jiyoun@naver.com

Received: December 24, 2018 / Accepted: January 22, 2019
This is an Open Access article distributed under the terms of the Creative Commons Attribution Non-Commercial License (http://creativecommons.org/licenses/by-nc/4.0/) which permits unrestricted non-commercial use, distribution, and reproduction in any medium, provided the original work is properly cited. 
of joints, and the progression of dementia occurs rapidly (Blondell et al., 2014).

In addition to this, among the nutritional problems that dementia patients have, malnutrition and weight loss are severe compared to the healthy old peoples (Gillette-Guyonnet et al., 2000). This kind of malnutrition is shown in a lack of ability to express desires such as hunger and an increasing lack of awareness about the need to take care of oneself (Orsitto et al., 2009). Also, inadequate nutrition and the abnormal nutrition conditions of the old people with dementia affect physical activities (Cugusi et al., 2014). As a result of that, it is the reason for a vicious cycle of health conditions, so parallel education about physical activity and nutrition is important.

Much previous research shows that guidelines for life including a healthy diet and regular exercise protect against dementia (Barnard et al., 2014). Healthy meals lower the risk of getting dementia in old age (Eskelinen et al., 2011). It has been reported that in the case of ingesting high calories (Luchsinger et al., 2002) or being overweight (Gustafson et al., 2003), the danger of Alzheimer type dementia increases. Also, research on oral supplements to solve the problem of the extreme malnutrition shown in severe dementia patients is in progress, but there is not enough research about how to provide nutrition treatment for mild dementia patients. In the case of dementia patients at a serious level in a facility, nutrition management is performed in the facility; on the other hand, education and management for mild dementia patients are not sufficient. To protect against dementia on the national level and to reduce medical expenses, education and treatment for mild dementia patients who are in the early stages of dementia are considered very important.

This research examines the influences on exercise function and change in eating habits with combined education in parallel with physical activity and a nutrition education program for mild dementia patients and tries to provide the basic data to develop a comprehensive education program for mild dementia patients with this.

\section{MATERIALS AND METHODS}

After getting approval from a dementia center for the old peoples in Incheon city, we visited there from April to July 2017 and performed a body composition and fitness check for 23 old patients who were diagnosed as having super mild or mild dementia. After performing an exercise program and nutrition education for 16 weeks, we completed the verification of effectiveness re-
Table 1. Distribution of the subjects

\begin{tabular}{lc}
\hline Variable & Mean \pm SD \\
\hline Age (yr) & $83.5 \pm 4.9$ \\
Height $(\mathrm{cm})$ & $148.77 \pm 7.75$ \\
Wight $(\mathrm{kg})$ & $72.76 \pm 11.20$ \\
WHR $(\%)$ & $0.94 \pm 0.07$ \\
Body mass index $\left(\mathrm{kg} / \mathrm{m}^{2}\right)$ & $25.05 \pm 5.41$ \\
MMSE-K (points) & $19.68 \pm 3.25$ \\
\hline
\end{tabular}

SD, standard deviation; WHR, waist-to-hip ratio; MMSE-K, Korean version of Mini-Mental State Examination.

garding physical health function and change in eating habits.

\section{Subjects}

The targets of this study are old patients with mild dementia who are using a dementia center for the old people in Incheon city, and it was performed for 23 old patients who were diagnosed as having super mild or mild dementia (Table 1). They were old patients who recently experienced cognitive disorders and emotional disorders, and the range of mild dementia was shown to be scores from 15 to 23 in the Mini-Mental State Examination (MMSE). We explained the purpose and goal of the research to the organization chief at the old dementia center and asked for cooperation. The patients themselves or their guardians listened to the explanation of the study's purpose, and the targets for the survey were selected from those who agreed to participate in writing.

\section{Exercise program}

A fine motor exercise program for the old people with mild dementia is composed of stretching, the main exercise, and cooling down. The main exercise is classified by the goal of the fine motor exercise, stretching, and coordination exercise such as sensory-motor and manipulative exercise, and the level of difficulty, which progressed by exercise period, is divided into three levels and is gradually increased. In addition to this, we used music to help people to adjust to the program without getting bored and to enjoy the program. We also composed an exercise program for the targets to continue the exercise habit by themselves even after the program was over. The exercise program ran for $1 \mathrm{hr} 5$ times a week, and was conducted by a visiting professional exercise instructor twice a week and by an instructor in the organization. The detailed program composition is as follows in Table 2.

\section{Senior fitness test}

This study performed a senior fitness test, or SFT, to verify the exercise function. In accordance with Rikli and Jones (1999), we 
Table 2. Composition of exercise program for mild dementia

\begin{tabular}{|c|c|c|c|c|}
\hline Classification & Purpose & Exercise movement by step & Time period & Duration of time \\
\hline \multirow[t]{6}{*}{ Warm-up exercise } & Stretching & Right and left extension of waist & 1-8Weeks & $5 \mathrm{~min}$ \\
\hline & & Shoulders & & \\
\hline & & Elbows & & \\
\hline & & Fingers & & \\
\hline & & Pushing palm & & \\
\hline & & Tapping & & \\
\hline \multirow[t]{23}{*}{ Main exercise } & Emotional exercise & Grabbing an object & 1-2 Weeks & $25 \mathrm{~min}$ \\
\hline & & Roll a tool with palm & 3-5 Weeks & \\
\hline & & Roll a tool with sole of foot & & \\
\hline & & Moving arm by grabbing an object & 6-8Weeks & \\
\hline & Manipulative exercise & Shifting a ball right $\rightarrow$ left $\rightarrow$ right & 1-2 Weeks & \\
\hline & & Grab a ball with two fingers & 3-5 Weeks & \\
\hline & & Grab a ball after throwing it & & \\
\hline & & Roll a ball & 6-8 Weeks & \\
\hline & & Exchange a ball with a partner & & \\
\hline & Coordination exercise & Push with a ring finger & 1-2 Weeks & \\
\hline & & Move toes & & \\
\hline & & Make a diagonal pattern of both hands & 3-5 Weeks & \\
\hline & & Rock-paper-scissors & & \\
\hline & & Make symmetry of rock-paper-scissors & 6-8 Weeks & \\
\hline & & Crumple newspaper with hands & & \\
\hline & & Crumple newspaper with feet & & \\
\hline & Recreation & Throw balls into basin as many as possible & 1-2 Weeks & \\
\hline & & Dart play - throw a ball and hit a stood-up paper cup & & \\
\hline & & Relay - pile paper cups & 3-5 Weeks & \\
\hline & & Move balls & & \\
\hline & & Hit an object by covering eyes with a towel & & \\
\hline & & Bowling play - roll a ball and hit a stood-up paper cup & 6-8Weeks & \\
\hline & & Drop-the-handkerchief game & & \\
\hline \multirow[t]{2}{*}{ Cool-down exercise } & Stretching & Repetition of warm-up exercise & 1-8 Weeks & $10 \mathrm{~min}$ \\
\hline & & Talk about today's exercise & & \\
\hline
\end{tabular}

used the following tests at the beginning of the study and after 16 weeks.

\section{0-sec chair stand test}

Purpose: To assess the lower-body strength needed for numerous tasks such as climbing stairs, walking, and getting out of a chair, bathtub, or car (increased ability in performing this exercise may reduce the possibility of falling).

Description: It consists of the number of times the patient comes to a full standing position from a seated position in $30 \mathrm{sec}$ with arms folded across the chest.

\section{0-sec arm curl test}

Purpose: To assess the upper-body strength needed for perform- ing household and other activities involving lifting and carrying things such as groceries, suitcases, and grandchildren.

Description: It consists of the number of biceps curls that can be completed in $30 \mathrm{sec}$ while holding a hand weight of 5 pounds $(2.3 \mathrm{~kg})$ for women.

\section{2-min step test}

Purpose: This is an alternative aerobic endurance test to be used when time restraints and/or space limitations impede administering the 6-min walk test.

Description: It consists of a number of full steps completed in 2 min, raising each knee to a point midway between the patella and the iliac crest; the score is the number of times the right knee reaches the required height. 


\section{Chair sit-and-reach test}

Purpose: To assess lower-body flexibility, which is important for good posture, normal gait patterns, and various mobility tasks, such as getting in and out of a bathtub or car.

Description: The patient is seated in a chair with legs extended. $\mathrm{He} / \mathrm{she}$ is instructed to keep their back straight and reach the toes with both hands. The number of inches $(\mathrm{cm})$ between the extended fingers and the tips of the toes are measured.

\section{Back scratch test}

Purpose: To assess upper-body (shoulder) flexibility, which is important in tasks such as combing one's hair, putting on overhead garments, and reaching for a seat belt.

Description: The patient puts one hand over the same shoulder with the palm touching the back and reached down the back. He/ she places the other hand up the back from the waist with the palm facing outwards. Pointing the middle fingers of each hand towards each other, patient tries to touch the fingers of each hand in the middle of the back. The number of inches $(\mathrm{cm})$ between the extended middle fingers are measured. The test is always done with the right hand over the shoulder and the left behind the back.

\section{8-foot up and go test}

Purpose: To assess the agility and dynamic balance that is important in tasks that require quick maneuvering, such as getting off a bus in time, getting up to attend to something in the kitchen, going to the bathroom, or answering the phone.

Description: It is the number of seconds required to rise from a seated position, walk 8 feet $(2.4 \mathrm{~m})$, turn, and resume the seated position.

\section{Mini nutrition assessment}

We conducted the MNA to search for the possibility of malnutrition in the old peoples, using a checklist first developed in Europe (Vellas et al., 2005). This checklist is composed of a basic evaluation with six questions and level 2 evaluation with 12 questions. The basic evaluation part has general questions about weight, changes in meal size, body mass index, physical activity, and mental problems. The level 2 evaluation includes more detailed items such as drugs taken, the number of daily meals, protein food intake condition, intake of vegetables, fruit, and water, whether one can eat alone, and evaluation of nutritional conditions. For each question, a score of 0, 0.5, 1, 2 is given according to the options, and the basic evaluation is 14 points, and level 2 evaluation is 16 points, on a scale of 30 points in total. If the total score is above 23.5, it is normal. If it is above 17 and below 23.5, it is at risk for malnutrition, and if it is less than 17 , it is judged to be malnourished.

\section{Nutrition education}

Nutrition education was given 16 times, once a week, and each education session lasted for $20 \mathrm{~min}$. The main contents of nutrition education were divided into four fields: the concept of health, proper eating habits, nutrition and nutrients, and the problems of hyper nutrition and nutrient deficiency. In the concept of health, contents about the definition of health and the importance of exercise and taking nutrition were included. Also, in proper eating habits, contents about the importance of breakfast and a balanced diet, and in nutrition and nutrients, contents about each kind of nutrition and role, food supply, sugar, sodium, trans fat, and reading nutrition labeling are included. Other than this, considering that the targets are the disabled, we asked questions about health and nutrition while conducting the exercise program every day, and continuously progressed the rechecking time about nutrition education contents.

\section{Data analysis}

The data was analyzed with the IBM SPSS Statistics ver. 23.0 (IBM Co., Armonk, NY, USA) program. All measured values are marked with mean \pm standard deviation and frequency. We used a paired $t$-test for effect before and after executing the program and verified the significance around the level of $P<0.05$.

\section{RESULTS}

\section{SFT change}

The SFT changes of participants after applying the exercise and nutrition education program are as follows in Tables 3 and 4 . Af-

Table 3. Change of senior fitness test at pre- and postintervention

\begin{tabular}{lccc}
\hline Variable & Pre & Post & $P$-value \\
\hline Chair stand test (number in $30 \mathrm{sec}$ ) & $10.86 \pm 2.01$ & $10.38 \pm 1.24$ & 0.234 \\
Arm curl test (number in $30 \mathrm{sec}$ ) & $12.35 \pm 7.89$ & $14.05 \pm 6.80$ & $0.001^{* * *}$ \\
2-min step test $(\mathrm{m})$ & $68.2 \pm 15.7$ & $74.9 \pm 16.2$ & $0.001^{* * *}$ \\
$\begin{array}{l}\text { Chair sit-and-reach test } \\
\quad \text { (cm from fingers to toe) }\end{array}$ & $-2.64 \pm 0.74$ & $-1.41 \pm 1.44$ & $0.003^{* *}$ \\
$\begin{array}{l}\text { Back scratch test } \\
\quad \text { (cm between middle fingers) }\end{array}$ & $-18.20 \pm 1.42$ & $-18.22 \pm 2.45$ & 0.341 \\
8-Foot up and go test (sec) & $9.98 \pm 1.01$ & $9.52 \pm 0.64$ & 0.841
\end{tabular}

Values are presented as mean \pm standard deviation.

${ }^{* *} P<0.01 .{ }^{* * *} P<0.001$. 
Table 4. Change of mini-nutrition assessment at pre- and postintervention

\begin{tabular}{lccl}
\hline Score & Pre & Post & $P$-value \\
\hline Basic test score $(\leq 14)$ & $9.48 \pm 2.37$ & $9.69 \pm 2.57$ & 0.855 \\
Secondary test score $(\leq 16)$ & $9.78 \pm 2.12$ & $11.28 \pm 2.03$ & $0.004^{* *}$ \\
Total score $(\leq 30)$ & $19.16 \pm 3.76$ & $21.07 \pm 4.12$ & $0.010^{* *}$ \\
\hline
\end{tabular}

Values are presented as mean \pm standard deviation.

${ }^{* *} P<0.01$.

ter performing the program for 16 weeks, we confirmed significant changes in the arm curl test $(P<0.001)$, chair sit-and-reach test $(P<0.003)$, and 2 -min step test $(P<0.001)$.

\section{MNA change}

The total score of MNA increased significantly from 19.16 to 21.07 before and after the subjects participated in the program $(P<0.010)$. In particular, in the level 2 evaluation that contains more detailed items such as drug taking condition, number of daily meals, protein food intake condition, intake of vegetables, fruit, and water, whether one can eat alone, and evaluation of nutritional conditions, there was a significant increase from 9.78 to $11.28(P<0.010)$.

\section{DISCUSSION}

This study performed research on exercise function and change in eating habits according to the application of exercise and a nutrition education program with the target of 23 old patients diagnosed with mild dementia, which falls under MMSE scores from 15 to 23 .

The purpose of the exercise program used in this study is therapeutic exercise for mild dementia patients. After applying the program for 8 weeks to mild dementia patients, it was reported that there was a significant increase in the ability to perform daily life activities (Choi et al., 2018). In addition, the SFT, which was used as an index of exercise function, includes lower limb muscles, upper limb muscles, cardiovascular endurance, flexibility in the upper and lower limbs, and the examination of quickness/balance. The SFT is evidence data from measuring more than 7,000 old men and women from 60 to 94 years old in 268 places in 21 countries in the world, and a normative score was formed, and the validity and reliability of this examination were reported (Rikli and Jones, 1999). This does not need special types of equipment and performance, and scoring of this examination is easy, and it is widely used as a safe method to measure the fitness of the old people.
As a result of the SFT in this study, there was a significant increase in the arm curl test $(P<0.001)$, chair sit-and-reach test $(P<$ 0.003), and 2-min step test $(P<0.001)$. In other words, it means an increase in the functions of upper limb muscles, flexibility, and endurance. Marmeleira et al. (2017) reported that exercise ability is remarkably low in the old people with a cognitive disorder, and functional disorders such as falls and health issues are shown. In a study by Todde et al. (2016) which ran parallel with regular exercise for 12 weeks for the target of the old people over 65 years old, a significant increase in function in all items was reported, except for the 8-foot up and go test, and this supports the results of this study. The effect of regular exercise is not influenced by the level of cognitive disorder. When exercise is performed under a professional guide's supervision, it is reported that exercise for more than 60 min 2 or 3 times a week is helpful to improve physical function (Lam et al., 2018). It is also reported that regular physical activity decreases the danger of Alzheimer type dementia (Larson et al., 2006), and improves blood flow and oxygen delivery by maintaining the brain function (Rogers et al., 1990). By suppressing the loss of hippocampal formation of tissue in the brain where aging progresses, the cognitive function of the old people improved (Colcombe and Kramer, 2003; Kramer and Colcombe, 2018).

By comparing this to the advanced study, this is a positive study result that can verify that the exercise program applied to this study, which is composed of fine motor exercise and stretching, and a phased program of coordination exercise is a proper program for the old people with dementia.

In the case of old patients with dementia, the frequency of malnutrition is higher than for normal old people, and this has an influence on complications, morbidity, and death rate later (Izawa et al., 2006). In effect, as in the study of Orsitto et al. (2009), malnutrition and the danger of malnutrition were high in people with mild cognitive disorder and the old people with dementia in MNA. Malara et al. (2014) reported that there was a significant correlation between MNA and MMSE. As a result of MNA conducted on patients with a mild cognitive disorder according to the MMSE, it was 19.16, which corresponds to the malnutrition risk group, and it increased significantly to 21.07 after executing nutrition education for 16 weeks. In addition, in a level 2 evaluation, which contains more details such as the condition of taking drugs, number of daily meals, protein food intake condition, intake condition of vegetables, fruit, and water, whether one can eat alone, and evaluation of nutritive condition, there was a significant increase from 9.78 to 11.28. Although this score corresponds 
to the danger of malnutrition, this can be a positive result that can explain the possibility of protecting against malnutrition by constantly performing the education program.

Physical composition and physical conditions such as weight loss significantly influence the improper nutrition condition of the old people with dementia (Cugusi et al., 2014; Kramer and Colcombe, 2018). Also, physical function and nutrition condition influence cognitive ability (Rahman et al., 2007). As a result of conducting the regular physical activity program and nutrition education for mild dementia patients, there was a significant increase in upper limb muscle strength, flexibility, and endurance. As a result of nutrition education performed in addition to this, there was a significant increase in nutrition condition, although it corresponds to the danger of malnutrition. Although we did not analyze various and influence factors that affect cognitive function, physical function, and nutrition or make a comparison with a control group, we were able to verify significant results by comparing before and after the program. It has significance to provide exercise for mild dementia patients and basic empirical data of dietary life nutrition education. We tried to contribute to making a comprehensive health program for mild dementia patients including the contents above.

\section{CONFLICT OF INTEREST}

No potential conflict of interest relevant to this article was reported.

\section{REFERENCES}

American Psychiatric Association. Diagnostic and statistical manual of mental disorders. 5th ed. Washington, DC; American Psychiatric Association; 2013.

Barnard ND, Bush AI, Ceccarelli A, Cooper J, de Jager CA, Erickson KI, Fraser G, Kesler S, Levin SM, Lucey B, Morris MC, Squitti R. Dietary and lifestyle guidelines for the prevention of Alzheimer's disease. Neurobiol Aging 2014;35 Suppl 2:S74-78.

Blondell SJ, Hammersley-Mather R, Veerman JL. Does physical activity prevent cognitive decline and dementia?: a systematic review and meta-analysis of longitudinal studies. BMC Public Health 2014;14:510.

Choi MR, Kim JY, Yi ES. Development and validation of exercise rehabilitation program for cognitive function and activity of daily living improvement in mild dementia elderly. J Exerc Rehabil 2018;14:207-212.

Colcombe S, Kramer AF. Fitness effects on the cognitive function of older adults: a meta-analytic study. Psychol Sci 2003;14:125-130.
Cugusi L, Solla P, Zedda F, Loi M, Serpe R, Cannas A, Marrosu F, Mercuro G. Effects of an adapted physical activity program on motor and non-motor functions and quality of life in patients with Parkinson's disease. NeuroRehabilitation 2014;35:789-794.

Eskelinen MH, Ngandu T, Tuomilehto J, Soininen H, Kivipelto M. Midlife healthy-diet index and late-life dementia and Alzheimer's disease. Dement Geriatr Cogn Dis Extra 2011;1:103-112.

Gaudreau P, Morais JA, Shatenstein B, Gray-Donald K, Khalil A, Dionne I, Ferland G, Fülöp T, Jacques D, Kergoat MJ, Tessier D, Wagner R, Payette $H$. Nutrition as a determinant of successful aging: description of the Quebec longitudinal study Nuage and results from cross-sectional pilot studies. Rejuvenation Res 2007;10:377-386.

Gillette-Guyonnet S, Nourhashemi F, Andrieu S, de Glisezinski I, Ousset PJ, Riviere D, Albarede JL, Vellas B. Weight loss in Alzheimer disease. Am J Clin Nutr 2000;71:637S-642S.

Gustafson D, Rothenberg E, Blennow K, Steen B, Skoog I. An 18-year follow-up of overweight and risk of Alzheimer disease. Arch Intern Med 2003;163:1524-1528.

Izawa S, Kuzuya M, Okada K, Enoki H, Koike T, Kanda S, Iguchi A. The nutritional status of frail elderly with care needs according to the mininutritional assessment. Clin Nutr 2006;25:962-967.

Kim H, Yoshida H, Suzuki T. The effects of multidimensional exercise on functional decline, urinary incontinence, and fear of falling in community-dwelling elderly women with multiple symptoms of geriatric syndrome: a randomized controlled and 6-month follow-up trial. Arch Gerontol Geriatr 2011;52:99-105.

Korea National Statistical Office. Population projections for Korea: 20102060 (based on the 2010 Census). Daejeon (Korea): Korea National Statistical Office; 2011.

Kramer AF, Colcombe S. Fitness effects on the cognitive function of older adults: a meta-analytic study-revisited. Perspect Psychol Sci 2018;13: 213-217.

Kwong EW, Pang SM, Aboo GH, Law SS. Pressure ulcer development in older residents in nursing homes: influencing factors. J Adv Nurs 2009; 65:2608-2620.

Lam FM, Huang MZ, Liao LR, Chung RC, Kwok TC, Pang MY. Physical exercise improves strength, balance, mobility, and endurance in people with cognitive impairment and dementia: a systematic review. J Physiother 2018;64:4-15.

Landi F, Abbatecola AM, Provinciali M, Corsonello A, Bustacchini S, Manigrasso L, Cherubini A, Bernabei R, Lattanzio F. Moving against frailty: does physical activity matter? Biogerontology 2010;11:537-545.

Larson EB, Wang L, Bowen JD, McCormick WC, Teri L, Crane P, Kukull $\mathrm{W}$. Exercise is associated with reduced risk for incident dementia among persons 65 years of age and older. Ann Intern Med 2006;144: 
73-81.

Luchsinger JA, Tang MX, Shea S, Mayeux R. Caloric intake and the risk of Alzheimer disease. Arch Neurol 2002;59:1258-1263.

Malara A, Sgrò G, Caruso C, Ceravolo F, Curinga G, Renda GF, Spadea F, Garo M, Rispoli V. Relationship between cognitive impairment and nutritional assessment on functional status in Calabrian long-term-care. Clin Interv Aging 2014;9:105-110.

Marmeleira J, Ferreira S, Raimundo A. Physical activity and physical fitness of nursing home residents with cognitive impairment: a pilot study. Exp Gerontol 2017;100:63-69.

Orsitto G, Fulvio F, Tria D, Turi V, Venezia A, Manca C. Nutritional status in hospitalized elderly patients with mild cognitive impairment. Clin Nutr 2009;28:100-102.

Ozaki A, Uchiyama M, Tagaya H, Ohida T, Ogihara R. The Japanese Centenarian Study: autonomy was associated with health practices as well as physical status. J Am Geriatr Soc 2007;55:95-101.

Rahman A, Sawyer Baker P, Allman RM, Zamrini E. Dietary factors and cognitive impairment in community-dwelling elderly. J Nutr Health Aging 2007;11:49-54.

Rikli RE. Jones CJ. Functional fitness normative scores for community-residing older adults, ages 60-94. J Physiother 1999;7:162-181.

Rogers HB, Schroeder T, Secher NH, Mitchell JH. Cerebral blood flow during static exercise in humans. J Appl Physiol (1985) 1990;68:23582361.

Todde F, Melis F, Mura R, Pau M, Fois F, Magnani S, Ibba G, Crisafulli A, Tocco F. A 12-week vigorous exercise protocol in a healthy group of persons over 65: study of physical function by means of the senior fitness test. Biomed Res Int 2016;2016:7639842.

Vellas B, Lauque S, Gillette-Guyonnet S, Andrieu S, Cortes F, Nourhashémi F, Cantet C, Ousset PJ, Grandjean H; REAL.FR Group. Impact of nutritional status on the evolution of Alzheimer's disease and on response to acetylcholinesterase inhibitor treatment. J Nutr Health Aging 2005; 9:75-80. 